HOLLY S. GOLDMAN

\title{
THE 'COLLECTIVE' INTERPRETATION OF UTILITARIAN GENERALIZATION
}

(Received 27 July, 1977)

Utilitarian Generalization (UG) is the theory that an act is right if and only if the consequences of everyone's performing that sort of action would be at least as good as the consequences of everyone's performing any alternative sort of action. A standard issue raised by the theory is how we specify what 'sort' an action is for purposes of applying the theory. According to David Lyons, the action's 'sort' is determined by all and only its 'consequentially significant' properties, i.e., those in virtue of which it produces utilities or disutilities. ${ }^{1}$ This implies that in certain cases the action's sort must refer to the activities of other agents, for they form an important part of the action's circumstances which contribute to the production of its consequences.

In applying UG, one must determine what the consequences would be of everyone's performing acts of the relevant sort; this in turn requires one to determine how many agents will have the opportunity to perform acts of this sort. ${ }^{2}$ But, as Sobel and Silverstein have pointed out, the question 'How many agents can perform acts of type $A$ ?' can be interpreted in two different ways. $^{3}$ On the more natural distributive interpretation, the question means 'How many agents will have as individuals the opportunity to perform an act of type $A$ ?' Since there are insurmountable difficulties with the theory on this interpretation, these investigators have urged a second, or collective, interpretation, according to which the question means 'How many agents can perform acts of type A collectively or together?' Clearly the answers to these two questions are different, for, when two people pass each other on the street without saying anything, both have the opportunity as individuals to be the only one to say 'hello', but it is possible for only one of them to perform this act when they are viewed as a collectivity.

In a previous paper I argued that the distributive version of UG (on a Lyons-type interpretation) cannot be used by agents as an action-guide, since in many cases an agent who attempts to use it in deciding whether or not to perform an act of type $A$ cannot determine how many agents will have the 
opportunity to perform acts of type $A$ without taking into account whether or not he himself is going to perform that act. ${ }^{4}$ Since an action-guide cannot require an agent to employ information that he will actually perform a given act in deciding whether or not to perform it, this is a grave defect in UG. The following case shows how the problem arises. Smith, Jones, and Brown are voting on a certain issue on which the majority rules. Smith and Jones will vote 'no', and Brown is attempting to use UG in deciding whether or not to vote 'yes'. His choice is represented in the following diagram:

$\begin{array}{llll}\text { Smith } & \text { Jones } & \text { Brown } & \begin{array}{l}\text { Utility of } \\ \text { Total Consequences }\end{array} \\ \text { no } & \text { no } & \text { yes } & 3 \\ \text { no } & \text { no } & \text { no } & 3\end{array}$

Brown's act of voting 'yes' must be described, according to Lyons' criterion, as an act of voting 'yes' in a context where two 'no' votes are cast and where two 'no' votes are sufficient to ensure a utility of 3 . Let us call this an act of type $Y$. How many agents have the opportunity (distributively) to perform an act of type $Y$ ? The answer is indeterminate unless we include information about how Brown himself votes: for if he votes 'yes', then only one person, himself, actually has this opportunity, whereas if he votes 'no', then all three agents have the opportunity (each could vote 'yes' in a context where two 'no' votes are cast). Brown cannot use UG in deciding what to do, since he cannot calculate the consequences of everyone's performing an act of type $Y$ unless he knows what he himself will do.

Silverstein has argued that the collective interpretation of UG avoids this problem. ${ }^{5}$ On this interpretation, if Brown votes 'yes', then only one person can (in the collective sense) perform an act of type $Y$ (i.e., Brown). But it is also true that if Brown votes 'no' then only one person can (in the collective sense) perform an act of type $Y$ - three may have this opportunity as individuals, but it is collectively possible for at most one of them to carry it out. Thus the number of agents with this collective opportunity is invariant with respect to Brown's own actions, and he need not use information about himself in making his decision.

However, Silverstein fails to notice that this argument does not hold for every possible act type. Let us focus on Brown's voting 'no', which must be described as "voting 'no' in a context where two other 'no' votes are cast and where two 'no' votes are sufficient to ensure a utility of 3". How many agents 
have the collective opportunity to perform an act of this type, type $N$ ? If Brown himself votes 'yes', then he is the only one with this opportunity, since he is the only one whose circumstances include the casting of two 'no' votes. But if he votes 'no' himself, then all three agents have this collective opportunity, as evidenced by the fact that all three actually perform acts of this sort! Thus the number of agents who have the collective opportunity to perform an act of type $N$ does vary with Brown's actual choice. Once again we discover that UG, even on the collective interpretation, cannot be used as an action guide. The only recourse seems to be deleting reference to the actions of others in specifying the 'sort' of the act under consideration.

\section{The University of Michigan}

\section{NOTES}

1 David Lyons, Forms and Limits of Utilitarianism, Oxford University Press, London 1965), p. 57.

2 Throughout this article I use the 'non-conditional' interpretation of 'having the opportunity to perform an act'. For a discussion of the 'conditional' interpretation, see Harry S. Silverstein, 'Goldman's "Level-2" Act Descriptions and Utilitarian Generalization', Philosophical Studies 30 (1976), 45-55, and Holly S. Goldman, 'Reply to Silverstein', Philosophical Studies 30 (1976), 57-61. Silverstein holds that using the collective interpretation even in conjunction with the non-conditional one is sufficient to rescue UG from the problem I sketch below.

3 J. Howard Sobel, "Everyone", Consequences, and Generalization Arguments', Inquiry 10 (1967), 373-404, and 'Utilitarianisms: Simple and General', Inquiry 13 (1970), 394-449; Silverstein, op. cit., pp. 47-48.

4 Holly S. Goldman, 'David Lyons on Utilitarian Generalization', Philosophical Studies 26 (1974), 89-90.

5 Silverstein, op. cit., pp. 47-50. 